\title{
ACHIEVING ACADEMIC PROMOTION: THE ROLE OF WORK ENVIRONMENT, ROLE CONFLICT, AND LIFE BALANCE
}

\author{
ELIZABETHBOWERING \\ MOUNT SAINT VINCENT UNIVERSITY
}

\author{
MAUREEN REED \\ RYERSON UNIVERSITY
}

\begin{abstract}
Fifty-two faculty at two Canadian universities were interviewed about the impact of work environment, role conflict, and worklife balance on career-related experiences and decisions to apply for promotion to full professor. Faculty described conflicts between their academic responsibilities of teaching, research, and service (including limited time for research despite long work weeks) as well as work-life imbalance. These issues were often gendered; women took slightly longer to achieve the rank of associate professor, accepted tasks of lower reward value, held decreased expectations for promotion, and experienced workplace conflict and bullying more than their male counterparts. Even so, faculty identified colleagues as a valuable career support. Our data lead us to theorize that the decision to apply for academic promotion is informed by a cost-benefit analysis, early career experiences, conformity with academic norms that over-emphasize research productivity, as well as access to career-advancing resources (especially time for research). We recommend that the gendered nature of the academic reward system be re-imagined to promote equality, and provide suggestions as to how to do so.

Keywords: faculty, promotion, work environment, role conflict, work-life balance, gender
\end{abstract}

\section{Résumé}

On a interviewé cinquante-deux professeurs d'université sur l'impact de l'environnement de travail, des conflits de rôle, et de la conciliation travail-vie personnelle sur les expériences professionnelles et sur la décision de demander la promotion au statut de professeur titulaire. Les répondants se sont exprimés sur la difficulté de concilier leurs responsabilités d'enseignement, de recherche et de travail administratif (y compris le temps limité à consacrer à la recherche malgré de longues semaines de travail) aussi bien que sur le déséquilibre entre travail et vie personnelle. Ces problèmes avaient souvent un aspect genré : les femmes prennent un peu plus de temps pour arriver au rang de professeure agrégée, acceptent des tâches jugées de moindre valeur, et ont des attentes plus faibles en ce qui concerne la promotion, tout en étant confrontées à des conflits et à de l'intimidation en milieu du travail. Toutefois, les répondants ont souligné le soutien précieux des collègues. Nos données nous amènent à émettre l'hypothèse que toute décision de demander une promotion serait informée par une analyse coûts-avantages, par les expériences vécues en début de carrière, par la conformité à des normes universitaires qui accordent une importance démesurée à la productivité en recherche, et par l'accès à des ressources pour l'avancement de carrière (dont surtout du temps pour faire de la recherche). Nous recommandons que le caractère sexospécifique du système de récompense universitaire soit repensé afin de promouvoir l'égalité, et nous proposons des méthodes pour ce faire.

Mots-clés : corps enseignant, promotion, milieu de travail, conflit de rôles, conciliation travail-vie personnelle, sexe

\section{Introduction}

An academic career is one that is rich with possibilities, among them the opportunity to discover and share knowledge, and to prepare students to be lifelong learners who contribute to society. While academic faculty experience considerable job commitment and satisfaction (Catano et al., 2010; Jones et al., 2012), they also report that their career path is lonely, unclear, and scrutinized, thus creating opportunity for negative stress, disengagement, and 
burnout (Acker et al., 2012; Kawalilak \& Groen, 2010; Khan et al., 2018; Knight, 2010; Meng \& Wang, 2018). Sources of academic stress and strain include a high workload (work environment), conflicting work demands and expectations (role conflict), and conflict between work and non-work responsibilities (work-life imbalance) (Catano et al., 2010), each of which can interfere with realizing career satisfaction and success. The purpose of the current article is to better understand the impact of work environment, role conflict, and work-life balance on career advancement, particularly in the decision to apply for the rank of full professor. Our article re-addresses the limited, dated literature on Canadian faculty promotion.

\section{Work Environment}

Faculty members experience multiple stressors in their work environment, including early-career negative experiences, competing time demands engendered by multiple responsibilities, frequent performance evaluations (by students, peers, and administrators), lack of transparency in promotion requirements, and career-limiting bias (Catano et al., 2010; Cox Edmondson, 2012; Fox \& Xiao, 2013; Gardner \& Blackstone, 2013; Gentry \& Stokes, 2015; Luster-Teasley, 2012). While most tenure-stream faculty will be granted tenure (Acker et al., 2012), many never advance past the rank of associate professor (Gardner \& Blackstone, 2013). Explanations for the lack of career advancement abound and include the challenges of evaluation evident in the tenure review process (Acker et al., 2012; Acker \& Webber, 2017). From their review of the literature, Lawrence et al. (2014) suggest a link between working conditions (e.g., equitable treatment, work-related feedback, collegiality, mentoring) and perceived fairness of the tenure process (e.g., decisions based on merit), with early negative experiences diminishing job satisfaction and productivity.

It is well known that ongoing assessment of multiple areas of responsibility can create stress and even distress, as faculty report feeling they must "measure up" in teaching performance, student management, and research output during early-career annual reviews and tenure processes (Acker \& Webber, 2017, p. 546). Some studies show that evaluation of research obligations brings the most stress, in part because of competing teaching and service-related demands (McGinn, 2012; Meng \& Wang, 2018). When McGinn (2012) asked faculty to identify difficulties at work, individuals noted the limited time available for research, despite the fact that research activity is commonly seen as the most important factor for career advancement. Indeed, for many faculty the research requirements for promotion create considerable stress and may decrease self-efficacy.

As Carson et al. (2013) suggest, academia is a competitive system with an unclear path to success. Many authors have pointed out that promotion targets are neither transparent nor well-operationalized, that variations exist in the processes within and across university departments and faculties, and that the decision makers can lack adequate training (Jones et al., 2014; Lawrence et al., 2014; Luster-Teasley, 2012). Hirschkorn (2010) further suggests that review processes are filled with misinformation, including rumours about the value of teaching, research productivity and collaborations, and collegial interactions. Lacking the necessary instruction, support, and/or mentoring to figure out the rules, faculty members worry that their activities will not be seen as sufficiently meritorious by promotion committees (Hellsten et al., 2010; Lawrence et al., 2014; Luster-Teasley, 2012).

Other researchers contend that tenure and promotion processes contain inequities (e.g., gender, race, and ethnicity). Racialized faculty are less likely to be tenured and promoted than non-racialized peers despite success in publication (Wijesingha \& Ramos, 2017). Box-Steffensmeier et al. (2015) found that men are more likely to be tenured and promoted from assistant to associate professor rank than women. As well, Canadian data from 2016 demonstrate that females account for $48.5 \%$ of assistant professors, but only $43.0 \%$ and $27.6 \%$ of associate and full professors, respectively (Canadian Association of University Teachers [CAUT], 2018). Observation of skewed success rates may prompt women to delay their application for full professorship, thereby limiting career advancement (Gardner \& Blackstone, 2013).

Differential success rates may also reflect different priorities. While the value of research to career success is well understood, teaching and service-related experiences differ by gender. In comparison to black men, black women see teaching as relevant to promotion and struggle to decline service requests, especially those related to students. These choices are costly, leading women to experience increased strain and exhaustion (Griffin et al., 2013). To the extent that review processes favour male-pattern choices and experiences (Acker et al., 2012), teaching, research, and service-related be- 
liefs and behaviours will have significant consequences, including a slower career trajectory and lower earnings (CAUT, 2018).

\section{Role Conflict}

Faculty members engage in teaching, research, and service, with the relative proportions influenced by the institution (i.e., emphasis on research vs. teaching), faculty unions, and the federal government (e.g., research-specific funding priorities; Gopaul et al., 2016). More recently, attention has turned to the emotional experiences of faculty while carrying out work duties. While mixed emotions are associated with both teaching and research activities, pre-tenure faculty experience more positive emotions about teaching (e.g., enjoyment, pride, satisfaction) than research (e.g., frustration, loneliness, fear, hopelessness, envy, shame) (Stupnisky et al., 2019). Despite this, and while most faculty members see research and teaching as important with research informing teaching, over half of participants prefer to work on research (Gopaul et al., 2016), especially men (Todd et al., 2008). This drive toward research pursuits is not motivated solely by the promise of a reward (promotion); as Moher et al. (2018) point out, faculty engage in time-consuming research activities (e.g., participating in peer review) that will not be tangibly rewarded. In comparison to male faculty, women, regardless of academic rank, carry out more service, especially internal service (Guarino \& Borden, 2017). Women also report more student demands and "special favor" requests (El-Alayli et al., 2018, p. 136) and provide more (stress-inducing) non-academic care to students (Dengate et al., 2019). Women also spend more time on teaching duties (Todd et al., 2008); ironically, mounting evidence indicates that student evaluations are biased against female instructors (Mitchell \& Martin, 2018).

\section{Work-Life Balance}

Faculty members accommodate multiple roles (teaching, research, and service) that require a considerable investment of time and energy, often at the expense of personal and family needs. In fact, Lester (2015) notes that universities often have cultures that suggest that faculty do not have family responsibilities that require attention, and while work-life balance policies may signal the value of balance, culture can be such that leaves and accommodation (e.g., to manage ill health or child and elder care) are not helpful and can even be stigmatizing. Although policies are intended to minimize risk (e.g., stress, ill health, absenteeism), in reality they can increase institutional reach into personal lives (e.g., flexible working hours may increase hours worked at home; Saltmarsh \& Randell-Moon, 2015). These work-family conflicts directly predict faculty burnout, and do so by reducing participation in family and leisure pursuits (Zábrodská et al., 2018). In fact, work-related demands are a better predictor of the intention to leave a university than are family-related demands (e.g., household chores, dependent care; Watanabe \& Falci, 2016). In the end, the pull between work and personal life may decrease job satisfaction as well as the intention and means to pursue academic promotion.

While most tenure-stream faculty achieve tenure, many do not seek promotion to full professor for reasons that are not entirely clear. In the current study, we interviewed male and female faculty to ask about career-related intentions, experiences, progression, and outcomes. We were especially interested in whether their motivation and confidence for securing full professorship had shifted over time, and how their decision-making process to apply was impacted by work environment, role conflict, and work-life balance. The study is unique in that it solicits the perspectives of a relatively large sample of faculty who work within different environmental contexts-at either a small, primarily undergraduate, teaching-emphasis university or a large, comprehensive institution. Our data will assist us in theorizing about individual characteristics that influence decisions to apply for promotion to full professor.

\section{Methods}

We relied on Grounded Theory methodology to construct theory from data (Isaacs, 2014; Khan, 2014; Lingard et al., 2008; Tie et al., 2019). Here, we used purposive sampling of relevant faculty groups, generated data through interviews, and then used a comparative approach involving initial coding and categorization to identify constructs critical to the development of theory (see Data Analyses section). Following this, we continued with interviews, coding, and categorization to generate theory for revealed constructs. The data-dependent theories were then connected to the literature. 
An interview approach (vs. other approaches such as survey or focus group) was chosen because it allows for an in-depth discussion to be raised by the participant, which may reveal theoretical underpinnings. For example, while it is known that academic work stressors can include limited time for research (see Introduction), our interviews may reveal that time is a resource not equally distributed amongst rank and gender. As such, the interview approach allows the participant to express their perception on the issue and the interviewer to probe for deeper understanding, which allows for contextualizing issues within theory.

For several reasons, our interview format relied on semi-structured questions. As Adams (2015) states, semi-structured interviews fall between the closed question survey approach and the open-ended free flowing discussion. By including both closed and open-ended questions within the interview, follow-up can identify the "why and how" of responses (Adams, 2015, p. 493). Semi-structured interviews possess many advantages; for example, they allow for independent thought by participants, probing of issues raised, and the gathering of more detailed information. While including some standardized questions, the interview is conversational in tone, which may be more comfortable for participants and encourage expression and disclosure. Finally, they work well when the interviewer has strong knowledge of interview content (Adams, 2015; Woods, 2011).

\section{Participants}

A purposive sample of faculty ( $n=52$ ) held full-time appointments (tenure-stream) at the rank of assistant ( $n$ $=16)$, associate $(n=19)$, or full $(n=17)$ professor and were, on average, $37.9(S=3.6), 53.4(S=9.0)$, and 56.0 $(S=7.2)$ years of age, respectively. Twenty-nine identified as female and 23 identified as male. All but four participants had completed a PhD at the time of interview. The disciplines included applied and professional or business programs (37\%), social sciences (33\%), science and engineering (19\%), and humanities (12\%). Participants were from two universities located in different cities in Canada. While faculty at each university are unionized, 23 participants were from one institution that is small and primarily undergraduate in focus, with separate review procedures for applications for tenure and promotion. In contrast, 29 participants were from the second institution, which is large and comprehensive with a combined tenure and promotion review procedure (although some respondents indicated that they had been part of an earlier system that assessed tenure and promotion separately). Neither institution possessed a medical, dental, or law school at the time of this study.

\section{Apparatus and Procedure}

After ethics approval, faculty members were emailed (using publicly available university directories) a brief description of the research study and an invitation to participate. To protect privacy, each study author recruited (and later interviewed) only individuals with whom they did not have a personal or professional relationship. In an effort to attain sufficient interviews (i.e., at least five male and five female participants at each of three academic ranks at each of two universities), 130 requests for participation were made over the course of one year. Recruitment was hampered by the limited pool of male assistant professors at one university. The number of invitations was similar for men and women, and across faculties containing humanities, social sciences, science and engineering, and applied professional studies (e.g., business, communications, social work, education). These faculties were chosen because the disciplines within each faculty were similar across the two universities.

Interviews occurred after the faculty member responded to the recruitment email and provided (by email) consent to participate. Participants received the interview questions in advance of the interview. These interview questions had been developed following a thorough literature review. Before beginning the interview, each participant provided oral informed consent. A semi-structured audiotaped interview (approximately 60 minutes in duration) was then conducted by telephone (except for one respondent who preferred to meet face-to-face). Participants first provided demographic information (i.e., age, gender, current academic rank, date and discipline of their PhD), and then answered questions about seven themes: (1) experiences leading to promotion (i.e., time to appointment, tenure, and promotion; teaching preps while pre-tenure; publication output at different career stages; internal and external grant success; perceived review requirements); (2) time spent on each of teaching, research, and service; (3) confidence and motivation in achieving full professor; (4) challenges and barriers to tenure and promotion; (5) career setbacks; (6) supports for tenure and promotion; and (7) advice based 
on experience. Confidence in achieving the rank of full professor was measured using a 10-point scale (where one represented "not at all confident" and 10 represented "extremely confident").

Participants took as much time as needed to provide their responses. When answering questions, some consulted their CV while others volunteered that they had already done so in preparation for the interview. Most participants chose to review their interview transcript, with the transcript subsequently amended as necessary. Others declined to do so, indicating that they were confident in the accuracy of the information provided.

\section{Data Analyses}

The interview transcripts were anonymized to remove potentially identifying information. Initially, coding of the responses to the qualitative-style questions was carried out on a partial sample of 15 participants, because it enabled identification, categorization, frequency, and comparison of themes and issues raised by the individual and the group, thereby demonstrating common patterns as well as dissimilarities (Lingard et al., 2008). Themes that were identified as essential to theory building were then a focus of discussion in subsequent interviews where participants were encouraged to expand on issues as they were raised (as is typical in Grounded Theory; Tie et al., 2019). The coding of subsequent interviews was carried out by two raters who closely read the transcripts to identify and code themes, followed by discussion and resolution of areas of discrepancies. The commonality of a theme across transcripts was calculated as the percentage and number of participants who subscribed to that theme. These themes, categories, and constructs were compared to develop theory. In what follows, the findings are presented thematically, with work environment, role conflict, work-life balance, academic rank, and gender highlighted where appropriate. In contrast, the quantitative-style questions focused on the number of years to tenure and promotion; scholarly productivity; time spent on each of research, teaching, and service; weekly hours worked; and estimated time and confidence in the likelihood of promotion. Medians, $N$, and score ranges ( $R$; minimum response values to maximum response values) are provided by academic rank and gender where appropriate.

Confidence analyses, medians, and $R$ revealed no differences between the two universities for each of the following measures: age, time to initial appointment, time to tenure, time to promotion to associate professorship, time to promotion to full professorship, number of new courses prepared in the first five years, number of publications for tenure, number of publications for promotion to full professor, and the number of hours worked per week. As such, data were collapsed across the two university samples. We speculate that the lack of differences reflects the fact that academic culture is quite similar across universities, regardless of whether the institution is large or small, and research-intensive vs. teaching-focused. That is, academics are socialized from graduate school onward to understand that long days are the norm, research productivity is especially valued and rewarded (i.e., publish or perish), career evaluations (e.g., tenure decisions) are carried out at specific points in time, and that workplace competitiveness is commonplace (Acker \& Webber, 2017; Carson et al., 2013; Lawrence et al., 2014; Lester, 2015; McGinn, 2012).

\section{Results}

\section{Experiences Leading to Promotion}

We began each interview by asking the respondent about their experiences leading to promotion (i.e., time to appointment, tenure, and promotion; teaching preps while pre-tenure; publication output at different career stages; internal and external grant success; and perceived review requirements).

\section{Time to Appointment, Tenure, and Promotion}

Assistant and associate professors were appointed to their faculty position two years post-PhD (Mdn $=2$ years for each rank), while full professors required less than two years ( $M d n=1.5$ years). Associate and full professors typically earned tenure five years post-appointment. Male associate professors secured tenure more than one year faster than female associate professors ( $M d n$ $=3.5, R=2-8$ years and $M d n=5, R=3.5-7$ years, respectively). Most participants were promoted to the associate rank at the time of tenure. Of the five men and five women not promoted at tenure, promotion followed, on average, one and two years later for men and wom- 
en, respectively ( $M d n=1, R=1-2$ years; $M d n=2, R=$ 1-4 years). Men explained their delay as being systemic (e.g., a separate application requesting promotion was required at the time of their tenure review). While one woman was delayed for administrative reasons, women were more likely to offer internal attributions for their delay, including the impact from a negative pre-tenure review experience, wanting a stronger scholarly record (i.e., "waiting until I had more pubs"), advice (i.e., "others suggested that it was best to wait"), and not being motivated to apply. Finally, full professors required eight years ( $R=2-16$ years) to receive that rank after promotion to the associate rank.

\section{Teaching and Research Activities}

Associate and full professors prepared five courses during their pre-tenure years ( $M d n=5, R=2-12$ ). Further, current assistant professors reported preparing a median of 4.3 courses to date, with females reporting a higher number of courses than males ( $M d n=5, R=2-7$ and $M d n=3.5, R=0-9$ courses, respectively). Moreover, associate and full professors produced between 6.5 and 11 (associate $M d n=6.5, R=1-35$; full $M d n=11, R=$ $0-25)$ publications (including articles, books, and films) to secure tenure, which suggests that an active program of research was required for tenure. However, the current assistant professors, who have not yet completed their tenure period, reported more publications ( $M d n=13.5$, $R=1-30$ ) to date than those completed by associate and full professors for their tenure, though considerable variability exists, as indicated by the large range. Moreover, the publication format (i.e., whether a journal article vs. book or book chapter) did not explain the differential output; that is, the article, book, or chapter publication levels were equal or higher for the pre-tenure faculty than those reported for the entire tenure period of the associate and full professors. One possible explanation is that the expectations for scholarly output have risen over time, both for success at tenure review (i.e., publish or perish) and at hiring (Warren, 2019), and pre-tenure faculty are well aware of expectations to publish. As shared by a male assistant professor, "The big barrier in Canada is getting a tenure track job. There are many people with good CVs and then they get their tenure-track job and they know what they are doing at that point." Finally, to attain tenure, publication output for females ( $M d n=9, R=0-35$ ) was slightly lower than for males ( $M d n=11, R=2-27$ ), although the range varied greatly, perhaps reflecting dis- ciplinary norms and research challenges.

Based on median output, full professors reported 28.5 publications in support of their application to full professor (male $M d n=22.5, R=10.5-38$; female $M d n=31, R=$ 12-52). All but two (one associate and one full) associate and full professors indicated that they had sought internal funding and all but four (two associate and two full) stated that they had sought external funding. Fourteen of 16 assistant professors had applied for internal funding and 11 assistant professors had sought external funding (note that some were still very early in their careers).

\section{Perceived Requirements for Tenure}

Most respondents (regardless of gender and rank) indicated that proficiency in each of teaching, research, and service is required for tenure. While not dismissing the importance of research productivity for tenure, 30 of 52 respondents specifically mentioned student ratings while eight of 16 assistant professors highlighted peer ratings. Additionally, faculty expressed concern about the evaluation process, as captured by the following comment: "In most new jobs, you are on probation for only three or six months. But tenure is a marker of whether you get to stay or not." Most respondents ( 26 of 36 who were eligible) received their associate professorship at the time of tenure.

\section{Perceived Requirements for Full Professor}

Over half of the associate professors and most assistant professors chose not to answer the question regarding the requirements necessary for promotion to full professor. As expressed by an assistant professor, "To be honest with you, I don't really know because I don't really know what I need to establish for this next hurdle [of tenure]." Of the nine associate professors who did answer, impactful research, impactful teaching, and serving on impactful committees were most cited. One associate professor concluded that,

An established program of research is the really big thing, plus continuing teaching, but full professor is really about research. There are also unofficially expectations for service too, though they're not official. You would never get full professorship based on the service contribution but I think questions would be raised if you had not done any service.

In contrast, full professors (15 of 17) identified impactful research that includes publication and student 
supervision as being important. Further, eight full professors identified impactful teaching, while six full professors indicated that funding as well as university and faculty level committee service were needed. Males and females differed little in their beliefs as to what is required to be promoted to full professor.

\section{Summary: Work Environment and Role Conflict}

The work environment for faculty at every rank is busy, especially for pre-tenure professors who typically prepare about five new courses while publishing and applying for grants. In addition, publication levels of those not yet tenured, while variable, are on average equal or higher than the levels of publication for tenure that were achieved by those who are now associate and full professors, indicating a possible shift in norms. Further, female associate professors took more than a year longer than males to achieve tenure, and when associate status was not immediately granted on tenure, women took longer to achieve it, citing personal choice, advice, and administrative issues as explanations. Finally, role conflict is evidenced by the teaching preparations and research activity being undertaken during the early career phase, and the perceived teaching, research, and service requirements to attain full professorship. In noting the role conflict inherent in the journey to full professor, one respondent commented,

There is some language recognizing that people like myself with exceptional teaching and/or service can be considered. I really don't know, if I put in an application, there are no spelled-out criteria for what you need to meet. There is language there that I could make use of; personally, I don't know of any teaching-emphasis person who has applied for full and received it. That doesn't mean it hasn't happened. I suspect I could get it based on my teaching-emphasis history but I think that I would need to ramp up my scholarly activity.

\section{Time Spent on Teaching, Research, and Service}

Faculty estimated the percentage of time they spent on each of teaching, research, and service, as well as the hours worked weekly during the academic year (Table 1). During the pre-tenure period, as reported by faculty at different ranks, about half of their time was spent on teaching, $30-40 \%$ on research, and $20 \%$ on service. Despite the importance of research productivity for career success, females reported spending more time on teaching than did males (Mdn of $50 \%$ vs. Mdn of $40 \%$, respectively) but less time on research ( $M d n=30 \%$ vs. $M d n=40 \%$, respectively), though considerable variability was noted across participants (see Table 1). Faculty at every rank worked about 50 to 60 hours weekly during the academic year, with little difference by gender.

In contrast, estimates by associate and full professors to attain full professorship were about $30 \%$ for teaching, $40 \%$ for research, and $25 \%$ for service (Table 1). Faculty worked 50 hours or more weekly $(R=35-80)$ during the academic year in preparation for promotion to full professor. Tellingly, females worked more hours than males ( $M d n=58.8$ vs. $M d n=51.3$, respectively), although variability existed.

Over half of the participants (27 of 52), whether male or female, did not reduce the time spent on teaching and service to meet the tenure or promotion requirements, indicating that teaching is important. For example, one participant stated, "No, I did not. I enjoy research but I value teaching." Another respondent commented, "No, I had a high priority for my teaching. I do not want to turn students off from the academic world." Participants often reported that they spent extra time on their teaching and worked longer hours, although some acknowledged that efficiency improves with teaching experience. For example, one participant stated, "No, I could increase efficiency because I do not have so many new preps, and I have teaching experience."

Participants who reduced the time spent on teaching explained that the savings reflected their improved ability to prepare classes, improved course management, increased familiarity with course material, and general teaching experience. As one participant noted,

In a way, I am trying to work on strategies to reduce prep time, I will recycle old material but have revised courses to include guest lectures, films, and they will reduce prep time. I think the way I taught the course was more lecture heavy than I would want so I will bring in new ways to engage.

Another said, "Yes, I spent lots on service though. I have 
Table 1

Percentage of Time Spent on Research, Teaching, and Service and Estimated Weekly Hours

\begin{tabular}{lllll}
\hline Source & $\begin{array}{l}\text { \% Research } \\
\text { Mdn }\left(\mathrm{R}^{*}\right)\end{array}$ & $\begin{array}{l}\text { \% Teaching } \\
\text { Mdn (R) }\end{array}$ & $\begin{array}{l}\text { \% Service } \\
\text { Mdn (R) }\end{array}$ & $\begin{array}{l}\text { Hours worked } \\
\text { Mdn (R) }\end{array}$ \\
\hline For Tenure & & & & \\
Assistant $(n=16)$ & $30(15-60)$ & $60(20-70)$ & $17.5(5-30)$ & $50(40-80)$ \\
Associate $(n=18)$ & $37.5(0-50)$ & $47.5(40-80)$ & $20(0-40)$ & $60(37.5-90)$ \\
Full $(n=16)$ & $30(0-50)$ & $42.5(26.7-80)$ & $22.5(10-40)$ & $55(42.5-75)$ \\
All Female $(n=29)$ & $30(0-60)$ & $50(20-80)$ & $20(0-40)$ & $55(40-90)$ \\
All Male $(n=21)$ & $40(20-60)$ & $40(22.5-65)$ & $20(5-40)$ & $53.8(37.5-80)$ \\
\hline For Full & & & & \\
Associate $(n=12)$ & $40(20-60)$ & $32.5(20-60)$ & $20(5-60)$ & $50(37.5-80)$ \\
Full $(n=17)$ & $40(0-70)$ & $30(20-70)$ & $26.7(10-60)$ & $55(35-75)$ \\
All Female $(n=13)$ & $45(0-70)$ & $30(20-70)$ & $26.7(5-40)$ & $58.8(40-75)$ \\
All Male $(n=16)$ & $40(20-70)$ & $32.5(20-60)$ & $25(10-60)$ & $51.3(35-80)$ \\
\hline
\end{tabular}

Note. ${ }^{*} \mathrm{R}$ is the range from minimum to maximum value.

changed now that I have my full professorship, but I reduced my load during my move toward full professor. Now I teach mostly online and that helps get research done." One respondent identified that time allotted to teaching can be reduced by teaching in one's research area: "I have reduced teaching; teaching what is related to research helps-I put least time into teaching but put in a lot of effort into it."Another suggested that increasing student interest is helpful: "Fine-tuned it to grab student interest and reduce their emotional responses and this makes it less draining and less time consuming." Finally, another strategy included not teaching new courses:

I got strategic in workload by carefully choosing what courses I teach, avoiding new preps, having multiple sections of the same course, and I jam teaching into two days. I also duplicate office hours related to teaching (e.g., multiple sections have the same office hours).

Other time-saving strategies included reducing service. As one individual said, "The Chair wanted me to get tenure and suggested that I do no service because
I already had overdone service." Others, however, noted that while they became more efficient teachers, there was still pressure to engage in service activities.

Not really, I just worked more hours. I had to publish and attend conferences, and it takes work so I had to spend time on it. Because of service, I was under pressure to say yes to everything. I did not want to take any chances with my reputation so I did not turn down service requests.

Interestingly, some thought that the service requirements differed by gender. As eloquently noted by one woman,

The bulk of the service work is done by a handful of people that are disproportionately female. I was on committees that just took up so much time. I don't have the boundaries that I see some of my male colleagues [are] able to erect very simply.

Finally, differences were evident across cohort, though not gender. More assistant professors (13 of 16) 
currently in their tenure period reduced time for teaching and service to focus on tenure and promotion than did associate professors (five of 19) or full professors (five of 17) who were recalling their pre-tenure behaviour. That said, females and males were equally likely to reduce time on teaching and service to achieve tenure and promotion (12 of 29 and 11 of 23 , respectively).

\section{Summary: Work Environment and Role Conflict}

Faculty at every career stage devoted considerable time to their work (50 hours or more per week). Role conflict existed during the tenure stage, where faculty spent more time on teaching than research, likely due to course preparation. In comparison to males, females tended to emphasize teaching over research (despite understanding the importance of research productivity to career advancement). For promotion to full professor, faculty reported an increased focus on research. Further, while faculty acknowledged the value of teaching, they also recognized that efficiencies in teaching and service activities might increase the likelihood of achieving promotion.

\section{Confidence and Motivation in Achieving Full Professor}

We asked each respondent to think back to the time of hiring and to recall whether they believed that they would eventually become a full professor, their confidence that this would indeed occur (using a 10-point scale, where 10 is "extremely confident"), and the time necessary to do so. We then asked only the assistant and associate professors to consider the same questions based on their current perspective. The responses revealed differences by gender and academic rank.

At the time of hiring, most assistant professors (13 of 16) but fewer associate professors (seven of 19) or full professors (eight of 17) believed that they would become full professors, needing 10, 11, and 12.5 years respectively to do so. We speculate that assistant professors are very much aware of the significance of their strong publication record. Tellingly (and in line with real world outcomes), proportionally more males (15 of 23) than females (13 of 29) believed at the time of hiring that they would become a full professor.

At the time of hiring, assistant and full professors of each gender (Mdn ratings $=6.3$ to 7.5 ) as well as male associate professors ( $M d n=7$ ) were moderately confident that they would become a full professor. Strikingly, female associate professors expressed lower confidence $(M d n=3.8)$. To investigate further, we counted the number of faculty who expressed low confidence on hiring (i.e., a rating less than five) that they would achieve full professorship. Of the 29 women, nine reported low confidence, and a further five said they did not expect to obtain full professorship and so provided no rating of confidence. Tellingly, proportionally fewer males expressed low confidence: only four of 23 reported low confidence, while two others said they did not expect to obtain full professorship and so provided no rating.

Based on today's view, 24 of 35 assistant and associate professors (13 females, 11 males) predicted that they would achieve full professorship. Assistant and associate professors respectively estimated needing 12.3 and 14.3 years to achieve that rank. Participants expressed moderate confidence (based on median ratings). One participant stated,

When I first started, I did not think that full professor would happen but I do now. I did not see that I could get publications or the teaching effectiveness needed but once I got a grant and award, I changed my mind. I underestimated myself in ability. I did not have the confidence I should have.

However, six female and no male assistant and associate professors expressed low confidence; one female and two males did not expect to achieve full professor and so did not provide a rating. While some participants who stated that they would not become a full professor provided moderate ratings of confidence that they could achieve that rank, others who stated they would become a full professor provided low ratings of confidence. Their comments help to explain this. Some worried that pursuing promotion would adversely affect their happiness:

I could do it if I chose, I am not sure if I want to spend the time in life to pursue it as it does not matter so much to me, other things matter more. I am about happiness now. But I can see that I might be able to find it fulfilling.

Alternatively, others viewed the application process as burdensome: "No, it is a hassle to produce the file. You get no research done while preparing the dossier, and 
then must find people you do not know in your area to review."

During the interview procedure, each participant was asked if they currently are eligible for promotion to the next academic rank and, if so, whether they are motivated to apply. Motivations varied across individuals (e.g., one full professor commented that the encouragement of colleagues was instrumental in the decision to apply). Only one female assistant professor was eligible, but expressed confusion about the application process and felt disadvantaged, being unsure about maternity leave accommodations. In contrast, six female associate professors were eligible for promotion to full professor, with a further individual uncertain of her eligibility because she had not yet reviewed the requirements. Of the six women, three indicated that they will apply because of the strength of their publication record, and enjoyment of research (e.g., "I'm quite well published internationally now, I have grants, [l've] been to major conferences." Another expressed her enjoyment of research, saying, "I enjoy writing and the ideas are important."). However, three women indicated that they will not apply for promotion because of poor research productivity $(n=2)$ or prior negative experiences with university politics $(n=1)$.

In addition, seven male associate professors were eligible to apply for full professor, with a further individual unsure of his eligibility. Of the four individuals who will apply for promotion, two wanted to demonstrate that they can attain the rank and one was motivated by recognition and financial rewards.

There is a degree of prestige that comes with full professor and there is more money. So, if you want to not hit a pay ceiling then you must obtain promotion. It is not my primary motivator though, my motivation is to do good work and do quality teaching, and to pursue meaningful research and with that at the end of the day, if I have the requirements to fulfill the full professor, I might as well do it.

Another simply wanted to terminate the stress of ongoing evaluations: "I would like to exit from the oversight process, and the angst of worrying about promotion and justifying my work. It's bad for my health." In contrast, three individuals indicated that they will not apply for promotion. While two individuals expressed satisfaction with their current academic rank, one of them expressed concern about the external referee evaluation process:
"External referees are the problem as they apply judgements and level of rigor from their university that may not apply at mine. I will not apply for full professor." The third individual was hesitant to apply because of his low research productivity.

\section{Summary: Role Conflict}

Faculty were somewhat confident that they could achieve full professor and primarily cited their research productivity as the deciding factor (while understanding that teaching and service also matter). However, also clear was that some faculty have reservations about the application and evaluation process itself, seeing it as potentially unpleasant and time-consuming. Although motivations for pursuing promotion differ across individuals, it is clear that faculty carefully weigh possible rewards and costs when contemplating the prospects of academic promotion.

\section{Challenges and Barriers to Tenure and Promotion}

As the interview progressed, we asked each respondent about the challenges and barriers experienced in their journey to tenure and promotion.

\section{Challenges for Tenure}

Overall, nine faculty (seven females, two males) were challenged by teaching and service commitments, which impacted their time for research (Table 2).

As one participant explained, "I have a lot of grading and big classes and that's a huge investment of time that takes a lot of energy and doesn't leave much room for writing and research during the academic year." Another stated,

I was on every committee-you don't want to say no to your colleagues because they will be on your (review) committee down the road. How can you be successful? Some (i.e., more senior) colleagues forget what it is like to be in this place (i.e., starting out as a faculty member).

In addition, 15 faculty (nine females, six males) listed the following barriers: a lack of collaborators, lack of research skill, lack of research support, inability to obtain grants, poor research productivity, and little research recognition. For example, one participant noted about grantsmanship, 
Table 2

Number of Respondents (and Percentage) Identifying Challenges for Tenure

\begin{tabular}{llll}
\hline Issue & $\begin{array}{l}\text { All } \\
(n=52)\end{array}$ & $\begin{array}{l}\text { Female } \\
(n=29)\end{array}$ & $\begin{array}{l}\text { Male } \\
(n=23)\end{array}$ \\
\hline Teaching and service commitments N (\%) & $9(17 \%)$ & $7(24 \%)$ & $2(9 \%)$ \\
Personal issues N (\%) & $39(75 \%)$ & $24(83 \%)$ & $15(65 \%)$ \\
Bullying, lack of support N (\%) & $18(35 \%)$ & $14(48 \%)$ & $4(17 \%)$ \\
Research issues N (\%) & $15(29 \%)$ & $9(32 \%)$ & $6(26 \%)$ \\
Vague tenure criteria N (\%) & $12(23 \%)$ & $6(21 \%)$ & $6(26 \%)$ \\
\hline
\end{tabular}

You had to write the grant itself and be able to stand out from your peers, which you didn't learn in the PhD program. You know how to analyze data and to plan a research project but the proposal itself is more than this. You need to make sure that whoever reads the proposal finds a benefit for the organization.

Further, 12 professors (six females, six males) felt that the criteria and requirements for promotion were not clear. For example, one individual said,

It was difficult for me to understand what the norms were because they weren't clear to me. I went to workshops and talked to people and didn't understand what they were saying; for example, I was told that I should be getting pubs in certain journals...but what is that really telling you about my ability? The expectations are social and not about scholarly capacity. I had trouble acclimatizing to those notions.

Another stated,

The biggest barrier I see is that there are no real guidelines to achieving tenure. This is the most stressful aspect...it is very vague. You have to spend this amount of time doing this amount of activity. You have people telling you that it is not good enough to get tenure. We don't have access to what has been good enough for other people.

Eighteen professors (14 females, four males) listed a lack of support and bullying as a challenge to promotion. For example, one individual stated,
Sometimes when people get friendly with you in your school, you misinterpret how that is. I spoke to a very wise colleague at another university who said basically "Close your door and do your work. Lay low and do what you have to do and get through this." I was having a hard time. It was a struggle-I felt I was being bullied and there was a lack of understanding. But what saved me was that I started to go outside my school and I reached out to other colleagues in my faculty.

Another noted, "Typical political issues in department: though I was not involved, there were collegial conflicts and it was uncomfortable. I work from home to avoid discomfort."

Finally, 39 faculty (24 females, 15 males) listed personal issues as a challenge to promotion. Most often, personal issues reflected an inability to find work-life balance (identified by 23 faculty: 15 females, eight males). For example, "My family...were understanding that it's a challenging job. There were days that I had to work from home and spend evenings marking before holidays." Responsibility for care of children and elders was noted by $15(52 \%)$ women but only six (26\%) men. One man reflected that,

I took my parenting responsibilities seriously. But the baby did not sleep. It was hard to work being sleep deprived. My entire family paid the price for my work toward tenure. Life outside of academia was intense, my community and family had to help me to get by. It was shared work with my community that allowed me to do my work. 
Women specifically commented on the emotional fallout from attempting to meet the conflicting demands of work and children. One woman stated that,

It's hard, you have kids, you have all these responsibilities. I can't, I have little children so I can't occupy my weekend with working so intensely as I was before, working nights. Constantly balancing, it's a constant state of failure and trying to achieve balance.

Another said,

I had guilt-balancing my work and my child. In my first year, I worked at home a couple days per week but there were too many distractions. So, I switched to be in my office five days a week and I worked on public transit to and from work and while my child slept.

For some, work even invaded their maternity leave: "I worked on both of my mat leaves.... So even though I was technically on mat leave, I would put my kids down for a nap and run back to my desk."

To deal with challenges for tenure, faculty indicated that they need to do the following: (1) increase research productivity by scheduling time for research, finding collaborators and creating research teams, listen to feedback, and reduce time spent with students (12 females, five males); (2) reduce stress by gaining promotion knowledge and seeking support from colleagues, the institution, and family and friends (10 females, seven males); and (3) learn to cope with job demands through scheduling time to relax, working late, staying longer at work, pushing back tenure or reducing maternity leave, thinking about the positives of work, avoiding collegial drama, and learning to say no to others (eight females, three males; Table 3).

\section{Table 3}

Number of Respondents (and Percentage) Identifying Strategies to Address the Challenges of Tenure

\begin{tabular}{llll}
\hline Issue & $\begin{array}{l}\text { All } \\
(n=52)\end{array}$ & $\begin{array}{l}\text { Female } \\
(n=29)\end{array}$ & $\begin{array}{l}\text { Male } \\
(n=23)\end{array}$ \\
\hline Increase research productivity N (\%) & $17(33 \%)$ & $12(41 \%)$ & $5(22 \%)$ \\
Learn to cope with job demands N (\%) & $11(21 \%)$ & $8(28 \%)$ & $3(13 \%)$ \\
Reduce stress N (\%) & $17(33 \%)$ & $10(34 \%)$ & $7(30 \%)$ \\
\hline
\end{tabular}

\section{Challenges for Promotion to Full Professor}

As most faculty interviewed were simultaneously tenured and promoted to the associate rank, the challenge of promotion to full professor is experienced during the associate professor years. As such, only associate and full professors are included in the following (Table 4). Thirteen of 36 associate and full professors (five females, eight males) identified research-related issues (e.g., lack of funding, poor research productivity, lack of collaborators, lack of research support and skill, gaining recognition in the field) as a challenge to achieving full professorship. As stated by one individual, "Barriersexpectations around research, the individual and for publication. This was challenging because it was never clear what the bar was." Twelve professors (five females, seven males) also identified personal issues as barriers (e.g., work-life balance, child and elder care, stress, health, family issues, confidence). As an example, one participant explained, "Family with children has eased but now I have elder care. It is difficult to balance work and life." Further, work-related lack of support or bullying was identified as a barrier by 10 professors (five females, five males). As an example of lack of support, one participant stated: "Collegial resentment and that my colleagues did not know or understand what I was doing. This led to some problems when applying for full." Vague promotion criteria and high teaching and service commitments were also identified as challenges.

\section{Summary: Work Environment, Role Conflict, and Work-Life Balance}

Challenges to tenure were many, including role conflicts such as teaching and service interfering with research obligations, low research skill, and lack of collaborators. Other challenges included the struggle to balance per- 
Table 4

Number of Associate and Full Professors (and Percentage) Identifying Challenges for Promotion to Full Professor

\begin{tabular}{llll}
\hline Issue & $\begin{array}{l}\text { All } \\
(n=36)\end{array}$ & $\begin{array}{l}\text { Female } \\
(n=19)\end{array}$ & $\begin{array}{l}\text { Male } \\
(n=17)\end{array}$ \\
\hline Teaching and service commitments N (\%) & $5(14 \%)$ & $1(5 \%)$ & $4(24 \%)$ \\
Personal issues N (\%) & $12(33 \%)$ & $5(26 \%)$ & $7(41 \%)$ \\
Bullying, lack of support N (\%) & $10(28 \%)$ & $5(26 \%)$ & $5(29 \%)$ \\
Research issues N (\%) & $13(36 \%)$ & $5(26 \%)$ & $8(47 \%)$ \\
Vague promotion criteria N (\%) & $6(17 \%)$ & $5(26 \%)$ & $1(6 \%)$ \\
\hline
\end{tabular}

sonal and work lives, with some coping strategies further impacting home life. Further, challenges for tenure are voiced proportionally more often by female faculty (perhaps because the early-career stage coincides with the demands of beginning or raising a family). In contrast, challenges to promotion to full professor included role conflict (low research productivity), work environment (i.e., perceived lack of support and bullying), and work-life imbalance (i.e., stress, health, and family care issues), with the challenges to full professor less gendered.

\section{Career Setbacks}

The most common career setback was research-related, which was cited by 28 of 52 respondents, and included difficulties with publishing and grantsmanship (Table 5). Sixteen participants identified personal issues as setbacks, including health and stress, childcare demands, and family issues. Twenty participants (13 females, seven males) listed personal issues related to their job, including challenging students, difficulties in attaining an academic appointment, starting their academic career at an older age, being unsure of job priorities, an unfinished $\mathrm{PhD}$ at hiring, requirement to work on leaves, and little time for research due to other job demands. Finally, 11 participants (seven females, four males) identified workplace bullying as a setback. For example, one individual stated, "Harassment was the biggest setback; it took an emotional toll and a physical toll." Another stated, "I have also had students disrupt class and made difficult teaching situations where I was left to deal with it."

Participants were then asked how they dealt with the setbacks that they have faced. Some noted that setbacks are a natural part of the academic experience. One stated, "I think we all have these types of setbacks (grants, publishing, bullied by senior scholars) and they are normal. I have had lots of failures, but everyone does." Another commented,

I have had them but they are not really setbacks and I survive despite these things. I have had normal pitfalls but for faculty these are normal issues. Finally, I stopped trying to improve teaching scores but rather think about what I give them, teach them for value rather than evaluations. Overall, I have not had any real setbacks.

Others described steps they took to minimize the impact of a setback. With regard to research setbacks, faculty members described revising papers, re-applying for grants, and seeking assistance from colleagues and research staff. To deal with the stress of the job and personal issues, faculty members discussed taking accommodations (e.g., leaves), choosing to focus on family rather than the job, and finding outside advocates. As one full professor recalled, "What I did to combat this problem is look for opportunities to be freed up from other obligations. Getting a good balance is hard and I had to work nights and weekends."

\section{Summary: Work Environment, Role Conflict, and Work-Life Balance}

Work environment, role conflicts, and work-life balance were identified as career setbacks. Faculty members described a work environment where the expectations 


\section{Table 5}

Number of Respondents (and Percentage) Identifying Career Setbacks

\begin{tabular}{llll}
\hline Issue & $\begin{array}{l}\text { All } \\
(n=52)\end{array}$ & $\begin{array}{l}\text { Female } \\
(n=29)\end{array}$ & $\begin{array}{l}\text { Male } \\
(n=23)\end{array}$ \\
\hline Research setbacks N (\%) & $28(54 \%)$ & $16(55 \%)$ & $12(52 \%)$ \\
Personal job-related setbacks N (\%) & $16(31 \%)$ & $8(28 \%)$ & $8(35 \%)$ \\
Personal setbacks N (\%) & $20(38 \%)$ & $13(45 \%)$ & $7(30 \%)$ \\
Bullying N (\%) & $11(21 \%)$ & $7(24 \%)$ & $4(17 \%)$ \\
\hline
\end{tabular}

were unclear, little time to meet research obligations was afforded, bullying and incivility occurred, and grantsmanship and publishing were difficult. In addition, they described personal issues of health, stress, childcare, and family as affecting their progression. Yet, sadly, many faculty saw these issues as being typical of the academic culture, and ones that they must endure in order to climb the academic ladder. Interestingly, faculty suggested strategies that required personal coping efforts combined with adaptation to the academic culture, but generally neglected to speak to how the culture itself might change for the betterment of the individual.

\section{Supports for Tenure and Promotion}

During the interview, we also inquired about supports for tenure and promotion.

\section{Supports for Tenure}

Faculty spoke of receiving individualized supports for achieving tenure. Overall, 49 of 52 faculty talked of collegial support (often informal), institutional support (e.g., university administrators), and advocate support (e.g., union, outside colleagues, publication editors). Twenty-nine respondents noted support from partners, family, and friends during the tenure period. Support through workshops, university learning and teaching offices, and mentoring programs were less cited (each cited by eight or fewer individuals). Female and male faculty did not report different types of supports.

\section{Supports for Full Professor}

Associate and full professors identified the supports they have or had for promotion to full professor. Most often, collegial supports (identified by 25 of 36 participants) were named, which included support from individuals in administration and colleagues. Thirteen of 36 participants identified support from family and friends. Five faculty indicated that "someone" had clarified what was needed to become a full professor. The above supports were equally identified by male and female faculty. A few males, but no females, identified that funding ( $n$ $=3)$ and/or leaves $(n=4)$ assisted them in moving toward or achieving full professor, and one female but five males identified workshops as helping them prepare for full professor. Three males (two associate and one full professor) stated that there were no supports for seeking full professor.

\section{Summary: Work Environment}

Despite the barriers and difficulties reported for the tenure and promotion to full professor, faculty members identify their colleagues as their support for promotions (despite noting that episodes of bullying and incivility are not uncommon).

\section{Advice Based on Experience}

Thirty-nine individuals commented on their experiences with promotion, especially in regard to balancing research needs and productivity with non-research requests and duties. One individual stated,

Do not be afraid to say yes to something but when you do make it your own. When asked to do something, try to be aware of what you are perpetuating and how it might affect the larger culture of research. 
Another noted,

I think a lesson that took me a long time to learn was paying attention to what I was interested in. I found it hard to fit myself into others' models. Once I figured out that I should follow my own interest, I was able to connect with others and find others with similar interests. You must know or learn what you want [and] like to do and do it.

A few noted the assistance they had from colleagues and supervisors and recommended others solicit help in establishing a strong research program. "(I was) lucky as a grad student to find someone who used research expertise and got publications. Working with someone with experience in research is helpful for tenure."

Faculty members also offered advice for those seeking promotion and for administrators, based on their personal experience. One individual said,

I think in these academic jobs, some are very motivated but others less so, yet all would like to grow but no one pushes them and they settle into a job; and since they don't get feedback and they do not know how to grow, so they are underutilized. In a perfect world, people would have a coach and help them to move forward, in academia you don't have that. I think academics would be improved by having encouragement to move forward. There needs to be room for growth.

Another stated,

The way achievements are presented in a promotion file matter. This is a peer system and is also based on individual relationships. If you have a strong academic culture, you will get feedback, and those wanting promotion should seek feedback.

A few offered advice about the promotion application. One acknowledged, "I want to highlight the lack of information, especially when going for full professor. For example, you must have an 'impact' but what does impact mean?" One suggested, "Quote the promotion requirement article in the contract to show how your background meets each aspect. Don't be shy to explain any special need or unavoidable stoppage in your working life in your cover letter." Another added,

Advice I would give to others who seek promotion is to make sure you protect yourself so you do not get caught up in doing a lot of excess service work, and that is a factor for a lot of female faculty. Two, try to find out as early as you can the specifics for promotion; if you know the requirements for achieving tenure and promotion you can focus on them.

Another stated,

When asked about promotion, people tend to tell a story about a straight-line path to tenure, but they tend to tell their own story. There is more than one way to accomplish this and within reason, one can carve out their own path. I do believe that each step to promotion is about mutual decision making. What does the organization think of me and my file and if it is not successful, figure out how to change. If one cannot figure out how to be successful, then find something different. We need to have meaning in work and this is important to your own well-being.

Many individuals spoke of gendered issues in promotion. A few noted that parenting is not equal and that parenting small children demands more from women than male partners. Others stated that academic workload is also gendered, including interactions with students.

Female academics get way more pushback than male academics. Like, my office hours are full of people challenging their grades. And I talk to my male colleagues, "Like, how many grade appeals did you get?" "Oh, none, why, did you?" Like, I just had ten students, mostly men, contesting their grade, you know. You know, their authority is taken for granted and in ways that ours is challenged daily.

Another stated,

Equity issues limit women's ability to get ahead. I think it really is unfortunate that the interpretation for professional activity is narrow. It is often called service rather than professional. There should be a lot more consideration for service and both service and professional activity should count towards full.

Many believed that there was "systematic discrimination against women. Life circumstances...family support, obligations, children...can impact careers." 
Finally, a few advised that promotion requires resilience. As one said,

You will have setbacks in life and work but keep going. Figure out what is setting you back and do the work. At the end of the day, if you feel you are contributing to your area, you are successful.

\section{One said,}

A colleague said I had more than enough for full professor as I had more coming into the university than most did when applying for full professor. I applied and had a full positive review. You must have CONFIDENCE in the IMPORTANCE of what you have to say.

\section{Discussion}

In the current study, work environment, role conflict, and work-life balance were identified as significant challenges along the road to promotion, impacting the motivation to pursue full professorship and the confidence that a successful outcome would be achieved. Our data identify that when considering whether or not to apply for full professorship, faculty engaged in a decision-making process that is best characterized as deliberate, informed, and reflective. Specifically, we theorized that the decision processes include a cost/benefit analysis, consideration of the level of conformity to institutional norms, past experiences in promotion to tenure, and the level of opportunity/resource access, where time allotted for research is a pivotal resource. Our data further identify that components of the decision process are gendered, since the intersection of work environment, role conflict, and work-life balance disadvantages women.

The United Nations identifies gender equality as equal access to "socially-valued goods, opportunities, resources and rewards" (United Nations Population Fund, 2005, para. 2). Van den Brink et al. (2010) promote three overlapping theoretical perspectives on gender equality to explain the gendered nature of decisions made by university promotion committees. These perspectives identify/theorize that gender equality can be achieved by the following: (1) eliminating structural and procedural barriers to equal opportunity, (2) celebrating gender differences rather than pushing women to be more like men, and (3) acknowledging that many objective institutional norms are male-oriented and these norms should be challenged. Our data suggest that these perspectives on equality also apply to the decision process of faculty members thinking of applying to the rank of full professor. Moreover, our data support that the decision process to apply for full professor is further hindered for women, who are frequently at a disadvantage in terms of costs vs. benefits, adherence to institutional norms, past negative work experiences, and access to resources and opportunities that assist in promotion.

In what follows, we describe how our interview data collected across two university settings inform our theoretical perspective. In so doing, we also consider how structural and procedural barriers to equal opportunity may be dismantled (or at least reduced) in ways that acknowledge, encourage, and reward gender-distinct career pathways.

\section{Evidence from Work Environment}

In deciding whether or not to apply for promotion, our participants carefully weighed the potential rewards (i.e., career validation, increased status and prestige, financial remuneration) against possible costs (e.g., fear of negative evaluation, distress, decreased self-efficacy, negative gossip, loss of reputational status). In such an analysis, sometimes called rational decision making, individuals evaluate the likelihood of success of a possible action (such as the decision to apply for promotion) while considering alternative choices, including all benefits and costs (Larrick et al., 1990). Rational decision making is influenced by emotional considerations (i.e., protecting self-esteem, minimizing regret; Josephs et al., 1992), heuristics, values (Haward \& Janvier, 2015), and salient in-group norms (Louis et al., 2005; O'Meara, 2011). Norms themselves influence the perception of the consequences of behaviour and people tend to adhere to the norms that define their in-group (e.g., faculty working at a particular institution; Louis et al., 2005; O'Meara, 2011). Thus, cost-benefit considerations done by faculty in the current study are likely linked to perceived institutional norms, as these identify how individuals can achieve benefits (Louis et al., 2005). Park (1996) noted that the criteria for promotion of research, teaching, and service with an emphasis on research is a long-standing university norm. This norm continues today. When describing their experience, our participants consistently 
reiterated that the institutional norm of research being valued more highly than teaching or service was particularly influential in their thinking.

In keeping with their belief that career success is largely dependent on research productivity, our participants were not more than moderately confident of achieving full professorship, fearing that their publication and funding record would be insufficient to withstand rigorous scrutiny. This sense of uncertainty is a theme of their academic life, as scrutiny and performance reviews that identify institutional norms begin early on and continue throughout their career. As Acker and Webber (2017) rightly point out, faculty recognize that they must "measure up" (p. 546) in multiple domains during the tenure review process, with particular attention being paid to their research productivity (McGinn, 2012). Not surprisingly, performance reviews engender stress and even distress, and especially so given that tenure criteria are often unclear yet still must be achieved within a finite time frame (i.e., the academic norm of beating the tenure clock). For many academics, these early-career experiences lead them to believe that academic life consists of a series of stress-inducing hurdles with little guarantee of success, however defined.

Furthermore, our participants easily identified the relative importance of research, teaching, and service as normative, yet expressed considerable concern about the vagueness of these evaluation criteria (for example, the meaning of terms such as "impactful research"). Interestingly, faculty perceived unclear criteria in teaching and research domains, even though research outcomes are more easily quantifiable and publicly visible (i.e., number of refereed publications in high-impact journals) than are measures of teaching (e.g., student achievement, which is hidden within the confines of a classroom). As well, faculty differed in the performance evaluation criteria that they thought were important for promotion, which suggests that some faculty misunderstand which measurement outcomes matter most and/or believe that criteria can be fluid, shifting across context (e.g., that review committees are flexible in what they consider necessary and sufficient for promotion). Concerns about the vagueness of evaluation criteria have been echoed elsewhere, with many authors concluding that promotion criteria are not sufficiently transparent and hence can differ by academic discipline and with time (Gardner \& Blackstone, 2013; Hellsten et al., 2010;
Jones et al., 2014; Lawrence et al., 2014; Luster-Teasley, 2012). The implications are twofold. While vague criteria might potentially advantage applicants by allowing a wider range of activities to count toward promotion (Gardner \& Blackstone, 2013), vagueness hampers the member's ability to accurately self-assess, and then improve, performance. We speculate that unclear research-related criteria might especially penalize women. Inaccurate bench-marking of progress, when combined with the high service and student demands that women receive (El-Alayli et al., 2018; Guarino \& Borden, 2017), may lead women to give away their most precious commodity for promotion: time for research.

When faculty are knowledgeable about the tenure and promotion review processes and operate within a work environment that emphasizes collegiality, mentoring, constructive feedback, and equitable treatment, they may be more likely to perceive the tenure process as fair and equitable (see Lawrence et al., 2014). In contrast, negative work experiences may diminish job satisfaction, productivity, and even the motivation to seek promotion. In the current study, women were more likely to report unpleasant experiences at work: almost half of the women, but only $17 \%$ of men, reported experiences of bullying, incivility, and lack of support. Perhaps, for these and other reasons, fewer women than men believed that they would eventually achieve promotion to full professor; lower confidence ratings seemed related to generalized stress, confusing review processes, and the risk to reputation from negative review decisions. In fact, our female participants did take slightly longer to achieve promotion to the associate rank than did men; some women stated that the delay was due to advice given, poor scholarly productivity, and negative pre-tenure experiences. This finding is in keeping with the literature that convincingly demonstrates that men are more likely to be tenured and promoted from the assistant to the associate professor rank than women (Box-Steffensmeier et al., 2015) and that women are less well represented at correspondingly higher ranks (CAUT, 2018).

In making meaning of their career progress to date, some female participants specifically questioned whether female-pattern work experiences (e.g., high demands for service, students who challenge their authority) and life experiences (e.g., pregnancy, child and elder care) hinder their advancement, as these demands make time for research less accessible (Dengate et al., 2019; 
El-Alayli et al., 2018; Guarino \& Borden, 2017). Additionally, some men, but no women, indicated that funding and/or leaves assisted them in achieving full professorship, presumably by providing time for research. We theorize that resources that protect, and even increase, time for research engagement (e.g., grants, research leaves) are critical in setting up faculty to achieve full professorship. Sadly, our data suggest that time is a gendered resource.

As currently constructed, the academic culture prizes and rewards research success as it is hard evidence of knowledge creation and dissemination (and so publicly enhances institutional prestige and visibility). Bernheim (1994) theorized that individuals conform to norms to avoid loss of status. Our data suggest that faculty deviate from the research-emphasis norm because of their personal values and preferences (e.g., favour teaching over research endeavours; are especially responsive to student requests and needs; seek to limit personal stress by not seeking promotion). They also may be less reactive to how they are viewed by colleagues. Whatever the case may be, it is undeniable (especially to the general public) that the mission of universities extends beyond knowledge creation to include knowledge transmission, which prepares students to meaningfully contribute to society. And so, we are left to ask whether the academic work system sufficiently recognizes, responds to, and rewards contributions that are teaching- and service-oriented in nature, and supportive of knowledge transmission. This question is especially compelling given the gendered nature of work and time resources demonstrated in the current study.

In sum, decisions for promotion to full professor are influenced by the work environment, where faculty members learn both costs and benefits of application, understand that the university treats research productivity as normative, have both negative and positive early career experience around tenure, and have unequal access to resources that might help them achieve promotion (e.g., time allocation for research).

\section{Evidence from Role Conflict}

We theorize that access to resources (e.g., leaves, internal/external grants, time for research) is a pivotal consideration in the decision to apply for full professor. Because of university norms to weight research over other contributions, the opportunity to access time for research is critical and gendered. As such, the motivation to apply for full professorship may be decreased by the recollection of the role conflicts of pre-tenure life combined with the recognition that long hours continue to be the norm for those intent on achieving full professor status. To achieve tenure and associate professorship, participants reported juggling teaching, research, and service commitments that required in excess of 50 hours per week, which is in keeping with the findings of Gopaul et al. (2016). In recalling their journey, our participants described learning how to balance new course preparations, classroom management, student needs, and service demands while simultaneously mounting a research program, securing funding, and publishing. In the current study, despite the ever-present need to fulfill their research requirements, many participants spoke of their interest in students and enjoyment of teaching, and willingly committed many hours to their teaching, mentoring, and advising responsibilities, despite the scarcity of time for research. For these individuals, the obligation to student learning and development reflected deeply held personal values. This suggests that individuals were guided by personal values rather than institutional norms, putting aside the scarcity of time for research when deciding to focus on teaching (see Bascle, 2016). As they further matured as teachers, many participants learned skills and strategies that increased their classroom efficiency, which helped to address research-related role conflict.

Despite the satisfaction derived from teaching, our early-career faculty remained cognizant of the importance of their scholarly activity to their tenure success. And, in fact, our pre-tenure faculty were, on average, publishing more than senior colleagues did early in their career (which may speak to the evolving expectations for early-career faculty). Some authors have theorized that the drive to focus on research is not entirely based on the premise of securing the reward of promotion, but rather is part of the socialization experience whereby cultural norms are learned. As noted by Moher et al. (2018), faculty engage in time-consuming research-related activities (e.g., peer reviewer of manuscripts, reader of student dissertations, member of research ethics committee) that promise little tangible reward but instead satisfy the desire and obligation to give back to the academic community (Mamiseishvili et al., 2016). Alas, while commendable, if not held in check, these commitments serve to increase research-related role conflict and strain. 
Time to research is an opportunity that allows research growth in that it affords research engagement, planning, publishing, and grant writing, all of which are unlikely to be achieved without adequate time. Despite increasing work experience and well-intentioned collegial advice, research suggests that women carry more service and teaching-related duties (Dengate et al., 2019; Guarino \& Borden, 2017). Our study corroborates the finding that female faculty commit more time to teaching than male faculty, which may, if excessive, undermine research capacity (i.e., planning, publishing, and grant preparation). While this commitment to teaching may represent a laudable personal value (i.e., an orientation to helping and serving others), it also represents a gendered perspective about the division of academic work, and therefore gender equality. In its simplest form, gender equality is signalled by equal access to opportunities and norms that consider and celebrate gender differences (van den Brink et al., 2010). The observation of the lessened career trajectory and earnings observed in female faculty (CAUT, 2018) challenges the belief that gender equality exists in the academy. Our data suggest that the university reward system is one that favours men and insufficiently recognizes those who are most stretched by ongoing role conflicts: women. While further study of this issue is warranted, at the very least, the tensions experienced by female faculty who are negotiating the demanding rhythms of academic life underscore the need to identify appropriate institutional supports.

But identification of supports by itself is unlikely to be sufficient (indeed, it may even reinforce and perpetuate the current value system). Based on the current study, we find that the traditional reward structures may not sufficiently recognize the faculty who are most stretched by ongoing role conflicts. Undoubtedly, some academics believe that the current structure is as it should be, with those who benefit from the status quo resisting initiatives to create gender equality (Powell et al., 2018). All too often, gender equality policies are poorly practised, ignored, overlooked, treated only as guidelines, and even overturned by university committees (Roos et al., 2020; van den Brink et al., 2010). Despite this, many academics, perhaps especially women, favour re-imagining the promotion process to more highly value and reward teaching and service-related contributions, thus making the promotion system more equitable (Dengate et al., 2019).
Interestingly, Barrett and Barrett (2011) identified little difference in publication levels between genders (as was also shown in the current study). Thus, it is surprising that women are less often seen in higher ranks at universities. Barrett and Barrett suggest that since women have more obligations outside of their research program, their time is divided differently than is true of men, a suggestion that is consistent with our finding at the pre-tenure stage. They suggest the issue, then, is one of workload management, where women lose time over the course of their career. Despite little difference in publication levels between genders, women delay or even abandon the application to full professor. We surmise that many women do not expect to achieve a higher rank. This expectation is likely based on the normative values assigned to different work responsibilities. We believe that less gendered norms around promotion are needed, with more equal weighting across career duties. We see value in continuing the conversation about academic culture, values, and faculty promotion, and believe that the academic norms around what is valued for promotion should consider equality. However, we caution that policy is not enough. Mechanisms and processes must be in place to ensure that gender equality practices are followed.

In sum, role conflict informs our theory in that it pulls faculty away from the valued institutional norm (research), is the basis for many negative work experiences, especially in early career, and reduces access to resources (e.g., time for research). As a result, it influences the decision-making process in the application to full professor.

\section{Evidence from Work-Life Balance}

As Lester (2015) notes, university culture can suggest that faculty do not have significant commitments and responsibilities outside of work hours, which was convincingly demonstrated in the current study. Our faculty reported considerable work creep, with a corresponding loss of family, social, and leisure pursuits, including time spent with their children. We theorize that the intensity of work-life conflict strongly influences the decision-making process to apply for full professor, especially for women who report considerable stress and even guilt around their work and family obligations. We theorize that when there is an imbalance, it is seen as a cost, it is considered a negative work experience, and it leads to a loss 
of opportunity in time for research, all of which affect the decision to seek promotion. The imbalance also is gendered.

Women reported a considerable emotional and physical impact of work on their already busy lives. In fact, half of the women (but only $26 \%$ of men) stated that finding time for childcare and elder care was a key challenge, invading care responsibilities and maternity leaves, and causing guilt. While their comments do not specify whether the tension between personal life and work is self vs. externally induced, nonetheless, the distress experienced by these women is genuine as they fear that working less, even while on leave, may lead to career or reputational repercussions. The Council of Canadian Academies (2012) recommended more family-friendly initiatives and policies to rectify work-life imbalance. Yet, equality-sensitive initiatives and policies alone are insufficient (Roos et al., 2020) as women will often not fully access them for fear of negative scrutiny by colleagues (Lester, 2015). In the end, the lack of balance further reduces the time to research even when this resource is theoretically offered, and this disproportionately affects women. This loss of time to research puts women behind in career advancement.

In sum, academic life is characterized by role conflicts and work-life imbalances, with considerable overlap-and even interference-between the professional and the personal selves. It would not be a stretch to say that the ongoing intersection of the personal and professional can prove to be psychologically and physically tiring, and consequently may drain motivation to strive for further promotion, especially when coupled with the realization that senior colleagues with tenure continue to work long hours. How universities can better support their faculty to find balance between work and life responsibilities requires a multi-pronged approach. Suggestions include protecting and promoting research (through research leaves and internal funding), as well as ensuring the equitable division of labour that supports students and the academy as a whole. Ultimately, however, we need to realign our thinking to acknowledge that differing career paths are worthy of recognition through promotion.

\section{Implications and Suggestions}

It appears that when eligible for promotion to full professor, many faculty are still experiencing issues that were evident during the pre-tenure process. Understanding the decisions to seek or not seek promotion assists in understanding gender inequalities in academia. Our data suggest to us that these decisions consist of numerous factors including cost-benefit analysis outcome, level of conformity to the current evaluation norms, past positive and negative work experiences (especially pre-tenure), and access to resources that assist with research demands (most pivotal is time to research). Yet, when asked about career setbacks, many participants mentioned research setbacks (e.g., grant and publication rejections) as normal academic experiences. Jaschik (2012) reported, based on large sample COACHE survey data from Harvard University, that associate professors are less satisfied with their work environment than are other ranks. Post-tenure, associate workload may increase in areas that are inconsistent with promotion to the full professor rank (e.g., less time for research), and associate professors may not believe that they can balance teaching, research, and service demands (Azubuike et al., 2019). Given this climate, it may not be surprising that some associate professors do not apply for full professorship. The current study identified that some faculty do not apply for promotion because they do not believe that their academic record is sufficient, but others made an informed choice not to apply, even when they believed their research record to be sufficient. Other factors such as past experiences (e.g., the stress of evaluation) and current values (e.g., importance of family over research) impacted decisions to apply for promotion.

Research on gender inequalities suggests that while the tenure outcome is similar for men and women (i.e., most achieve tenure), the career pathways often differ. Obligations internal and external to work are different for women (Acker et al., 2012; Armenti, 2004; Guarino \& Borden, 2017; Lester, 2015). For example, women take on more service (especially internal service) than males (Guarino \& Borden, 2017). Some female participants in our study suggested that women do indeed experience more service and student demands. These demands further reduce available time for research and impact on the decision to seek full professorship.

One wonders how to address inequalities in the academic system. Creating gender-friendly policies and re-imagining reward systems, where all aspects of a career are weighted fairly (impactful teaching, research, and service; e.g., undergraduate director, departmental 
chair) may be a first step. Regardless, research identifies that when equality policies and initiatives are created, they are often resisted by the very people they are designed to assist and by evaluation committees (Roos et al., 2020). Even so, there is value to gender equality in identifying the varying pathways that faculty take to promotion and creating a reward system based on them. Addressing inequalities could include suggestions made by the Council of Canadian Academies (2012) such as part-time tenured positions, scholarship, grants, and outreach to women academics, as well as legal remedies for injustices such as pay inequity.

The current reward system for promotion is not balanced, being focused on research productivity. As a result, many faculty self-select out of the promotion process. Given that the system is gendered, women are most affected. Yet, faculty in our study did identify supports that assisted them in reaching the rank of full professor, including research leaves and university grants. Our faculty also reported that exposure to workplace conflicts and bullying created emotional distress and a sense of being devalued. Unfortunately, this too is more commonly experienced by women. Thus, a further initiative that might assist in workplace equality is mentoring from senior colleagues. Many faculty spoke of the benefits they received from having an informal mentor. Yet, informal mentors will sometimes provide advice that is difficult to implement (e.g., reduce teaching and service). Mentors should be trained to assist pre-tenure and associate professors with advice consistent with evaluations, and methods that truly assist (e.g., advice on grant writing, successful teaching pedagogies, teaching and research dossiers). Such mentors would benefit all genders. However, while peer mentoring can improve job satisfaction and facilitate promotion, associate professors are less satisfied with their mentoring experience than are assistant professors (Ockene et al., 2017; Wasserstein et al., 2007). To reiterate, then, peer mentoring as a resource for promotion requires examination of the specific needs of faculty at each academic rank as well as careful selection of peer mentors.

\section{Limitations}

Our study has produced several intriguing findings regarding the career experiences of Canadian faculty, as well as suggestions for further study. We would, for example, like to increase the generalizability of our data by including a broader sample of faculty (especially racialized individuals) across diverse university disciplines and contexts. In so doing, we would give voice to the lived experience of racialized faculty, who are understudied in the current sample. Due to sampling issues, we also cannot generalize results across all academic disciplines and workplace contexts (e.g., medical school faculty).

Additionally, we acknowledge possible selection and sample biases as well as methodological choices. That is, our research participants may be those who are actively reflecting on career experiences and choices, and so reflect a unique subgroup of academics. Given the precariousness of academic work, we also cannot speak to the experiences of faculty who have left tenure-stream positions for other career pursuits. Finally, for reasons of cost efficiency, our interviews were mostly conducted by telephone. However, we have no reason to believe that a face-to-face format would alter the responses that were provided.

\section{Conclusion}

To conclude, our investigation is a step toward understanding how work environment, role conflict, and work-life balance affect career decisions for promotion of Canadian faculty. Theoretically, we suggest that decisions to seek promotion involve evaluation of cost and benefits, one's level of conformity to institutional norms, past work experiences, and access to resources that assist in promotion, time to research being pivotal. We also highlight that the academic system for promotion is gendered and needs to be re-imagined for equality. The results suggest that academic life includes significant challenges and setbacks, with faculty experiencing considerable stress as they attempt to negotiate research- and non-research-related spheres of activity without sacrificing research productivity, and therefore career advancement. Given that faculty duties extend beyond research to encompass teaching and advising of students, we also believe institutions need to create better "time as a resource" through leaves and workload redistribution. Changes in the reward system, normative practices, and workload practices would increase equality in academic settings. 


\section{References}

Acker, S., \& Webber, M. (2017). Made to measure: Early career academics in the Canadian university workplace. Higher Education Research \& Development, 36(3), 541-554. https://doi.org/10.1080/07294360.2 $\underline{017.1288704}$

Acker, S., Webber, M., \& Smyth, E. (2012). Tenure troubles and equity matters in Canadian academe. British Journal of Sociology of Education, 33(5), 743-761. https://doi.org/10.1080/01425692.2012.6 74784

Adams, W. C. (2015). Conducting semi-structured interviews. In K. E. Newcomer, H. P. Hatry, \& J. S. Wholey (Eds.), Handbook of practical program evaluation (4th ed., pp. 492-505). John Wiley \& Sons.

Armenti, C. (2004). Gender as a barrier for women with children in academe. Canadian Journal of Higher Education, 34(1), 1-26. https://journals.sfu.ca/cjhe/ index.php/cihe/article/view/183445/183398

Azubuike, N. O., Benson, R. T., Kumar, A., \& Mathews, K. R. (2019). COACHE Summary Tables 2019: Selected dimensions of the faculty workplace experience, by institution type, discipline, rank (with tenure status), race/ethnicity, and gender. Harvard Graduate School of Education. https://docs.google. com/spreadsheets/d/e/2PACX-1vTWdPvjkGdVVc7hMZJ6M1D7B8xgw4GU2liF4TTcUSs5GnalP MM5btoDz9ux5k65qyYsTYJEyuJpLHo/pubhtml\#

Barrett, L., \& Barrett, P. (2011). Women and academic workloads: Career slow lane or cul-de-sac? Higher Education, 61, 141-155. https://doi.org/10.1007/ s10734-010-9329-3

Bascle, G. (2016). Toward a dynamic theory of intermediate conformity. Journal of Management Studies, 53(2), 131-160. https://doi.org/10.1111/joms.12155

Bernheim, B. D. (1994). A theory of conformity. Journal of Political Economy, 102(5), 841-877. https://www. haverford.edu/sites/default/files/Bernheim1994.pdf

Box-Steffensmeier, J. M., Cunha, R. C., Varbanov, R. A., Hoh, Y. S., Knisley, M. L., \& Holmes, M. A. (2015). Survival analysis of faculty retention and promotion in the social sciences by gender. PLOS ONE,
10(11), e0143093. https://doi.org/10.1371/journal. pone. 0143093

Canadian Association of University Teachers. (2018). Underrepresented \& underpaid: Diversity \& equity among Canada's post-secondary education teachers. https://www.caut.ca/sites/default/files/caut equity report 2018-04final.pdf

Carson, L., Bartneck, C., \& Voges, K. (2013). Over-competitiveness in academia: A literature review.

Disruptive Science and Technology, 1(4), 183-190. https://doi.org/10.1089/dst.2013.0013

Catano, V., Francis, L., Haines, T., Kirpalani, H., Shannon, H., Stringer, B., \& Lozanzki, L. (2010). Occupational stress in Canadian universities: A national survey. International Journal of Stress Management, 17(3), 232-258. https://www.researchgate. net/publication/232565678 Occupational Stress in Canadian Universities A National Survey

Council of Canadian Academies. (2012). Strengthening Canada's research capacity: The gender dimension. Expert Panel on Women in University Research. http://www.scienceadvice.ca/en/assessments/completed/women-researchers.aspx

Cox Edmondson, V. (2012). Reflections from a Black female in the promotion and tenure process. Gender in Management, 27(5), 331-345. https://doi. org/10.1108/17542411211252642

Dengate, M., Peter, T., \& Farenhorst, A. (2019). Gender and the faculty care gap: "The obvious go-to person" for Canadian university students' personal problems. Canadian Journal of Higher Education, 49(3), 104-114. https://doi.org/10.7202/1066638ar

El-Alayli, A., Hansen-Brown, A. A., \& Ceynar, M. (2018). Dancing backwards in high heels: Female professors experience more work demands and special favor requests, particularly from academically entitled students. Sex Roles, 79, 136-150. https:// doi.org/10.1007/s11199-017-0872-6

Fox, M. F., \& Xiao, W. (2013). Perceived chances for promotion among women associate professors in computing: Individual, departmental, and entrepreneurial factors. Journal of Technology Transfer, 38, 135-152. https://doi.org/10.1007/s10961-012-9250-2 
Gardner, S. K., \& Blackstone, A. (2013). "Putting in your time": Faculty experiences in the process of promotion to professor. Innovative Higher Education, 38, 411-425. https://doi.org/10.1007/s10755$\underline{012-9252-\mathrm{x}}$

Gentry, R., \& Stokes, D. (2015). Strategies for professors who service the university to earn tenure and promotion. Research in Higher Education Journal, 29, 1-13. https://files.eric.ed.gov/fulltext/ EJ1077941.pdf

Gopaul, B., Jones, G. A., Weinrib, J., Metcalfe, A., Fisher, D., Gringas, Y., \& Rubenson, K. (2016). The academic profession in Canada: Perceptions of Canadian university faculty about research and teaching. Canadian Journal of Higher Education, 46(2), 55-77. https://journals.sfu.ca/cjhe/index.php/ cjhe/article/view/185269/pdf

Griffin, K. A., Bennett, J. C., \& Harris, J. (2013). Marginalizing merit? Gender differences in Black faculty D/discourses on tenure, advancement, and professional success. Review of Higher Education, 36(4), 489-512. https://doi.org/10.1353/rhe.2013.0040

Guarino, C. M., \& Borden, V. M. H. (2017). Faculty service loads and gender: Are women taking care of the academic family? Research in Higher Education, 58, 672-694. https://doi.org/10.1007/ s11162-017-9454-2

Haward, M. F., \& Janvier, A. (2015). An introduction to behavioural decision-making theories for paediatricians. Acta Paediatrica, 104(4), 340-345. https:/l doi.org/10.1111/apa.12948

Hellsten, L. M., Martin, S., \& McIntyre, L. J. (2010). Navigating the potholes and speed bumps: Three female perspectives on tenure and promotion. Journal of Educational Thought, 44(1), 99-115. https://journalhosting.ucalgary.ca/index.php/jet/ issue/view/3135

Hirschkorn, M. (2010). How vulnerable am I? An experiential discussion of tenure rhetoric for new faculty. Journal of Educational Thought, 44(1), 41-54. https://www.researchgate.net/ profile/MarkHirschkorn/publication/269333473 How vulnerable am I An experiential discussion of tenure rhetoric for_'new' facultyl
links/5486f8360cf2ef34478e9d3f/How-vulnerable-am-I-An-experiential-discussion-of-tenure-rhetoric-for-new-faculty.pdf

Isaacs, A. N. (2014). An overview of qualitative research methodology for public health researchers. International Journal of Medicine and Public Health, 4(4), 318-323. https://doi.org/10.4103/2230$\underline{8598.144055}$

Jaschik, S. (2012, June 4). Unhappy associate professors. Inside Higher Ed. https://www.insidehighered.com/news/2012/06/04/associate-professors-less-satisfied-those-other-ranks-survey-finds

Jones, K., Beddoes, K., Banerjee, D., \& Pawley, A. L. (2014). Examining the flexibility bind in American tenure and promotion processes: An institutional ethnographic approach. Ethnography and Education, 9(3), 328-342. http://dx.doi.org/10.1080/17457 $\underline{823.2014 .911665}$

Jones, G., Weinrib, J., Metcalfe, A. S., Fisher, D., Rubenson, K., \& Snee, I. (2012). Academic work in Canada: The perceptions of early-career academics. Higher Education Quarterly, 66(2), 189-206. https://doi.org/10.1111/j.1468-2273.2012.00515.x

Josephs, R. A., Larrick, R. P., Steele, C. M., \& Nisbett, R. E. (1992). Protecting the self from the negative consequences of risky decisions. Journal of Personality and Social Psychology, 62(1), 26-37. https://doi.org/10.1037/0022-3514.62.1.26

Kawalilak, C., \& Groen, J. (2010). Illuminating the tenure-track pathway: A "new" faculty perspective. Journal of Educational Thought, 44(1), 131-146. https://www.jstor.org/stable/23767062

Khan, F., Khan, Q., Kanwal, A., \& Bukhair, N. (2018). Impact of job stress and social support with job burnout among universities faculty members. Paradigms: A Research Journal of Commerce, Economics, and Social Sciences, 12(2), 201-205. https:// paradigms.ucp.edu.pkl

Khan, S. N. (2014). Qualitative research method: Grounded theory. International Journal of Business and Management, 9(11), 224-233. https://doi. org/10.5539/ijbm.v9n11p224 
Knight, W. B. (2010). Sink or swim: Navigating the perilous waters of promotion and tenure: What's diversity got to do with it? Studies in Art Education, 52(1), 84-87. https://doi.org/10.1080/00393541.20 10.11518825

Larrick, R. P., Morgan, J. N., \& Nisbett, R. E. (1990). Teaching the use of cost-benefit reasoning in everyday life. Psychological Science, 1(6), 362-370. https://doi.org/10.1111/j.1467-9280.1990.tb00243.x

Lawrence, J. H., Celis, S., \& Ott, M. (2014). Is the tenure process fair? What faculty think. Journal of Higher Education, 85(2), 155-192. https://doi. org/10.1353/jhe.2014.0010

Lester, J. (2015). Cultures of work-life balance in higher education: A case of fragmentation. Journal of Diversity in Higher Education, 8(3), 139-156. https:/l doi.org/10.1037/a0039377

Lingard, L., Albert, M., \& Levinson, W. (2008). Qualitative research: Grounded theory, mixed methods, and action research. British Medical Journal, 337, 459-461. https://doi.org/10.1136/ bmj.39602.690162.47

Louis, W. R., Taylor, D. M., \& Douglas, R. L. (2005). Normative influence and rational conflict decisions: Group norms and cost-benefit analyses for intergroup behavior. Group Processes \& Intergroup Relations, 8(4), 355-374. https://doi. org/10.1177/1368430205056465

Luster-Teasley, S. (2012). Making tenure and promotion more transparent for underrepresented faculty. On Campus with Women, 41(1), 1. link.gale.com/apps/ doc/A298503860/AONE? $=$ =anon 40488732\&sid=googleScholar\&xid=6e2780e5

Mamiseishvili, K., Miller, M. T., \& Lee, D. (2016). Beyond teaching and research: Faculty perceptions of service roles at research universities. Innovative Higher Education, 41(4), 273-285. https://doi. org/10.1007/s10755-015-9354-3

McGinn, M. K. (2012). Being academic researchers: Navigating pleasures and pains in the current $\mathrm{Ca}-$ nadian context. Workplace: A Journal for Academic Labor, 21, 14-24. https://doi.org/10.14288/workplace.v0i21.182519
Meng, Q., \& Wang, G. (2018). A research on sources of university faculty occupational stress: $A$ Chinese case study. Psychology Research and Behavior Management, 11, 597-605. https://www.ncbi.nlm. nih.gov/pmc/articles/PMC6292231/pdf/prbm-11$\underline{597 . p d f}$

Mitchell, K. M. W., \& Martin, J. (2018). Gender bias in student evaluations. PS: Political Science \& Politics, 51(3), 648-652. https://doi.org/10.1017/ S104909651800001X

Moher, D., Naudet, F., Cristea, I. A., Miedema, F., Ioannidis, J. P. A., \& Goodman, S. N. (2018). Assessing scientists for hiring, promotion, and tenure. PLOS Biology, 16(3), e2004089. https://doi.org/10.1371/ journal.pbio.2004089

Ockene, J. K., Milner, R. J., Thorndyke, L. E., Congdon, J., \& Cain, J. M. (2017). Peers for promotion: Achieving academic advancement through facilitated peer mentoring. Journal of Faculty Development, 31(3), 5-13. https://www.ingentaconnect.com/ contentone/magna/jfd/2017/00000031/00000003/ art00001

O'Meara, K. (2011). Inside the panopticon: Studying academic reward systems. In J. C. Smart \& M. B. Paulsen (Eds.), Higher education: Handbook of theory and research (Vol. 26, pp.161-220). Springer. https://doi.org/10.1007/978-94-007-0702-3 5

Park, S. M. (1996). Research, teaching, and service: Why shouldn't women's work count? Journal of Higher Education, 67(1), 46-84. https://doi. org/10.2307/2943903

Powell, S., Ah-King, M., \& Hussénius, A. (2018). Are we to become a gender university? Facets of resistance to a gender equality project. Gender, Work and Organization, 25(2), 127-143. https://doi. org/10.1111/gwao.12204

Roos, H., Mampaey, J., Huisman, J., \& Luyckx, J. (2020). The failure of gender equality initiatives in academia: Exploring defensive institutional work in Flemish universities. Gender \& Society, 34(3), 467495. https://doi.org/10.1177/0891243220914521

Saltmarsh, S., \& Randell-Moon, H. (2015). Managing the risky humanity of academic workers: Risk and 
reciprocity in university work-life balance policies. Policy Futures in Education, 13(5), 662-682. https://doi.org/10.1177/1478210315579552

Stupnisky, R. H., Hall, N. C., \& Pekrun, R. (2019). The emotions of pretenure faculty: Implications for teaching and research success. Review of Higher Education, 42(4), 1489-1526. https://doi. org/10.1353/rhe.2019.0073

Tie, Y. C., Birks, M., \& Francis, K. (2019). Grounded theory research: $A$ design framework for novice researchers. SAGE Open Medicine, 7, 1-8. https:/l doi.org/10.1177/2050312118822927

Todd, Z., Madill, A., Shaw, N., \& Bown, N. (2008). Faculty members' perceptions of how academic work is evaluated: Similarities and differences by gender. Sex Roles, 59, 765-775. https://doi.org/10.1007/ s11199-008-9480-9

United Nations Population Fund. (2005). Frequently asked questions about gender equality. https:/l www.unfpa.org/resources/frequently-asked-questions-about-gender-equality

van den Brink, M., Benschop, M., \& Jansen, W. (2010). Transparency in academic recruitment: A problematic tool for gender equality? Organization Studies, 31(11), 1459-1483. https://doi. org/10.1177/0170840610380812

Warren, J. R. (2019). How much do you have to publish to get a job in a top Sociology department? Or to get tenure? Trends over a generation. Sociological Science, 6, 172-196. https://doi.org/10.15195/v6.a7

Wasserstein, A. G., Quistberg, D. A., \& Shea, J. A. (2007). Mentoring at the University of Pennsylvania: Results of a faculty survey. Journal of General Internal Medicine, 22(2), 210-214. https://doi. org/10.1007/s11606-006-0051-x

Watanabe, M., \& Falci, C. D. (2016). A demands and resources approach to understanding faculty turnover intentions due to work-family balance. Journal of Family Issues, 37(3), 393-415. https:/l doi.org/10.1177/0192513X14530972

Wijesingha, R., \& Ramos, H. (2017). Human capital or cultural taxation: What accounts for differences in tenure and promotion of racialized and female fac- ulty? Canadian Journal of Higher Education, 47(3), 54-75. https://doi.org/10.47678/cihe.v47i3.187902

Woods, M. (2011). Interviewing for research and analyzing qualitative data: An overview [PowerPoint slides]. Slideshare. https://owll.massey.ac.nz/pdf/ interviewing-for-research-and-analysing-qualitative-data.pdf

Zábrodská, K., Mudrák, J., Šolcová, I., Květon, P., Blatný, M., \& Machovcová, K. (2018). Burnout among university faculty: The central role of work-family conflict. Educational Psychology, 38(6), 800-819. https://doi.org/10.1080/01443410.2017.1340590

\section{Contact Information}

Elizabeth Bowering

elizabeth.bowering@msvu.ca 